\title{
RANCANG BANGUN SISTEM PENGONTROL BATCH MIXER PADA INDUSTRI MINUMAN DENGAN METODE PID BERBASIS ARDUINO UNO R3
}

\author{
Redi Permata Hati, Arkhan Subari \\ Program Studi DIII Teknik Elektro Departemen Teknologi Industri \\ Sekolah Vokasi Universitas Diponegoro Semarang \\ Jalan Prof. Sudharto, SH Tembalang Semarang
}

\begin{abstract}
Redi Permata Hati, Arkhan Subari, in this paper explain that batch Mixer is a tool that accommodates some of the raw materials to be mixed so that it becomes a usable product. Raw materials can be a liquid, solid and gas. The use of raw materials and way of mixing the raw materials that distinguish Batch Mixer design at each industry. In this thesis, design Batch Mixer consists of two tanks, namely the mixing tank and tank heaters. In the mixing tank, there HCSR-04 Ultrasonic sensor that functions as a detector of the level of the liquid level, and the stirrer motor-driven DC $12 \mathrm{~V}$. While the heater tank, there MAX6675 Thermocouple temperature sensor and heater. There are also three pumps that pump fluid 1, pump 2 and pump fluid mixing. Batch Mixer working process is controlled automatically using the Arduino Uno R3 displayed via HMI Raspberry Pi. The use Arduino Uno R3 allows users to create a variety of issues related to the microcontroller.

The control system is used to control the work process in a plant. The control system in the Batch Mixer works by two indicators: the water level and water temperature. In the manufacturing system, water temperature control using PID control (Proportional Integral Derivative) with PID tuning method to find the value of Kp, $K d$, and Ki. Based on test results, use the most optimal value for use PID control value Kp $=60, K i=0.005$ and $K d=0.5$. By using the value of the achievement level will be faster and the value of the maximum error of $2.5 \%$ is still within the tolerance limits of $3 \%$.
\end{abstract}

Keywords: Control Systems, Batch Mixer, Arduino Uno R3, Control PID (Proportional Integral Derivative).

\section{PENDAHULUAN}

Di dunia industri, proses produksi dikerjakan secara manual dengan menggunakan jasa tenaga kerja manusia mengakibatkan proses produksi berjalan lambat dan hasil produksi yang kurang ekonomis. Oleh karena itu dibutuhkan proses produksi yang dikerjakan secara otomatis dengan menggunakan mesin sebagai pengganti jasa manusia.

Proses produksi secara otomatis telah digunakan oleh berbagai industri, misalnya industri yang menghasilkan produk minuman, makanan, minyak, dan lain-lain. Proses produksi tersebut menggunakan suatu alat yang disebut dengan batch mixer.

Batch mixer merupakan alat yang menampung beberapa bahan baku untuk dicampurkan sehingga menjadi produk dapat digunakan. Bahan baku dapat berupa cairan, padat dan gas. Penggunaan bahan baku dan cara pencampuran bahan baku yang membedakan perancangan batch mixer pada setiap industri.

Pada industri minuman, proses produksi secara manual melibatkan banyak manusia untuk melakukan pencampuran beberapa bahan baku. Bahan baku tersebut ditampung pada sebuah tangki yang kemudian diaduk dan dipanaskan sehingga menjadi produk yang diinginkan.

Untuk mengetahui batch mixer berjalan dengan baik dapat dilakukan kontrol terhadap batch mixer dengan menggunakan mikrokontroller, PLC, atau perangkat yang lainnya. Namun mikrokontroller ini lebih banyak digunakan karena disamping hanya membutuhkan ruang yang relatif kecil mikrokontroller juga memiliki lebih banyak cara pemograman mulai dari Assembly ,Basic, C, dll. dibandingkan dengan PLC atau perangkat yang lainya.

Salah satu jenis mikrokontroller yang populer saat ini adalah Arduino, Arduino memiliki keunggulan dibandingkan dengan jenis mikrokontroller yang lain seperti CVAVR, Baskom dll. Arduino menggunakan bahasa pemograman yang lebih sederhana karena software arduino dilengkapi dengan kumpulan library yang cukup lengkap selain itu arduino sudah dilengkapi dengan port USB sebagai media untuk mengunduh program.

Pada industri minuman, mikrokontroller digunakan untuk pengaturan suhu dan water level control. Ada beberapa metode bisa digunakan diantaranya menggunakan metode fuzzy, PI dan PID. Pada prinsipnya metode dengan sistem kontrol ini hampir sama namun dengan menggunakan metode PID dapat mengurangi penggunaan energi listrik, serta menjadikan suhu air lebih presisi dan stabil.

\section{Batch Mixer \\ Batch mixer adalah adalah alat yang menampung beberapa bahan baku untuk dicampurkan sehingga menjadi produk yang dapat digunakan. Bahan baku dapat berupa cairan, padat dan gas. Penggunaan bahan baku dan cara}


pencampuran bahan baku yang membedakan perancangan batch mixer pada setiap industri. ${ }^{[1]}$

\section{Sistem Kendali (Control System)}

Sistem kendali atau yang disebut juga sistem kontrol adalah proses pengaturan ataupun pengendalian terhadap satu atau beberapa besaran variabel atau parameter. ${ }^{[2]}$

Ada dua sistem kontrol pada sistem kendali atau kontrol otomatis yaitu :

- Sistem Kontrol Loop Terbuka

Sistem kontrol loop terbukamerupakan sustu sistem kontrol yang nilai keluarannya tidak berpengaruh terhadap aksi pengontrolan.Dengan demikian pada sistem kontrol ini, nilai keluaran tidak di umpanbalikkan ke parameter pengendalian.

- $\quad$ Sistem Kontrol Loop Tertutup

Sistem kontrol umpan balik (feedback) atau close-loop merupakan sistem yang menggunakan hubungan antara output dan input yang diinginkan dengan cara membandingkannya. Hasil perbandingan ini merupakan deviasi yang digunakan sebagai alat kontrol.

Pengontrol akan mengurangi error dan membawa sistem pada keadaan yang diinginkan (output sesuai dengan input yang diinginkan).Jadi output akan mempengaruhi aksi kontrol. Pada sistem kontrol ini, keberadaan gangguan yang menyebabkan output menyimpang dari input yang diinginkan dapat diantisipasi. Sistem akan dikembalikan ke keadaan set point oleh pengontrol. Diagram blok sistem pengendalian loop tertutup ditunjukkan pada gambar 1 .

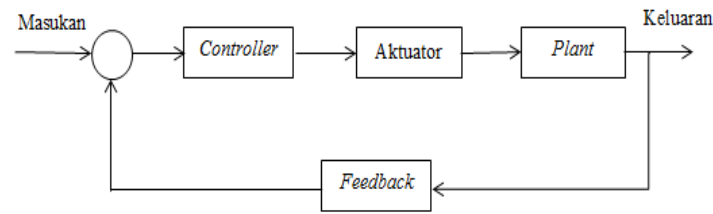

Gambar 1.Blok diagram sistem pengendalian Tertutup ${ }^{[1]}$

\section{Kontroler On-Off}

Kontroler On-Off hanya bekerja pada dua posisi, yaitu posisi "On" dan posisi "Off" . Kalau contoh objek yang akan dikontrol adalah valve, maka kerja valve hanya terbuka penuh atau tertutup penuh, valve tidak akan pernah bekerja di daerah antara $0-100 \%$. Karena kerjanya yang on-off hasil kontrol on-off akan menyebabkan output/process variable ber-osilasi penuh dan tidak pernah konstan.

\section{Kontroler PID}

Setiap kekurangan dan kelebihan dari masing-masing pengontrol $\mathrm{P}$, I dan $\mathrm{D}$ dapat saling menutupi dengan menggabungkan ketiganya secara paralel menjadi pengontrol proporsional plus integral plus diferensial (pengontrol PID). Elemen- elemen pengontrol P, I dan D masing-masing secara keseluruhan bertujuan

- Mempercepat reaksi sebuah sistem mencapai set point $\neg$-nya

- Menghilangkan offset

- Mengasilkan perubahan awal yang besar dan mengurangi overshoot

Dalam perancangan sistem kontrol PID yang perlu dilakukan adalah mengatur parameter $\mathrm{P}, \mathrm{I}$, atau D agar tanggapan sinyal keluaran sistem terhadap masukan tertentu sebagaimana yang diinginkan.

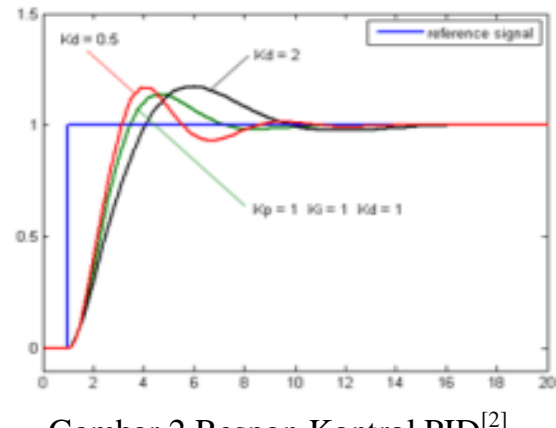

Gambar 2.Respon Kontrol PID ${ }^{[2]}$

\section{Arduino Uno}

Arduino Uno adalah arduino board yang menggunakan mikrokontroler ATmega328. ${ }^{[3]}$ Arduino Uno memiliki 14 pin digital (6 pin dapat digunakan sebagai output PWM), 6 input analog, sebuah $16 \mathrm{MHz}$ osilator kristal, sebuah koneksi USB, sebuah konektor sumber tegangan, sebuah header ICSP, dan sebuah tombol reset. Arduino Uno memuat segala hal yang dibutuhkan untuk mendukung sebuah mikrokontroler. Hanya denganmenghubungkannya ke sebuah komputer melalui USB atau memberikan tegangan DC dari baterai atau adaptor AC ke DC sudah dapat membuanya bekerja. Tampak atas dari Arduino Uno dapat dilihat pada gambar 3.

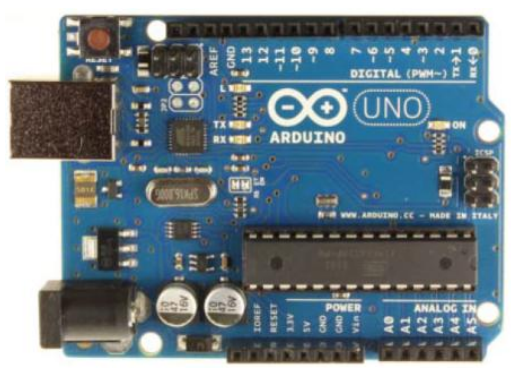

Gambar 3.Arduino Uno

\section{Thermocouple}

Thermocouple adalah salah satu jenis alat ukur temperature yang menggunakan prinsip termoelektris pada sebuah material. Alat ini tersusun atas dua konduktor listrik dari material yang berbeda yang dirangkai membentuk sebuah rangkaian listrik. Besar tegangan listrik yang terbentuktergantung dari jenis material konduktor yang digunakan, dan besar perbedaan temperatur antara dua konduktor tersebut. 
Komponen utama dari thermocouple adalah dua jenis logam konduktor listrik yang berbeda yang dirangkai sedemikian rupa sehingga pada saat salah satu logam terkena sumber panas, sedangkan logam yang lain temperaturnya tetap, maka rangkaian tersebut akan menghasilkan tegangan listrik tertentu yang nilainya sebanding dengan temperatur sumber panas. Sinyal yang keluar dari thermocouple berupa voltase mikrovolt. Maka pada rangkaian thermocouple diperlukan rangkaian amplifier agar sinyal keluaran dapat dibaca oleh perangkat digital.

- Thermocouple Tipe K

- Bahan logam konduktor positif : Nickel-I Chromium

- Bahan logam konduktor negatif : Constantan

- Rentang Suhu :-200 C-1250C

\section{Sensor Ultrasonik}

Untuk mengukur tingkat ketinggian cairan dapat dilakukan menggunakan sensor ultrasonik yang dipasang di bagian atas dari tabung. Sensor ini terdiri dari pemancar dan penerima Pemancar ultrasonik memancarkan gelombang ultrasonik, ketika gelombang ultrasonik mengenai cairan, maka sinyal ini dipantulkan, dan diterima oleh penerima ultrasonik. Selama menunggu pantulan, pengirim ultrasonik akan menghasilkan sebuah pulsa. Pulsa ini akan berhenti ketika gelombang pantulan terdeteksi oleh penerima ultrasonik. Oleh karena itulah lebar pulsa tersebut dapat merepresentasikan jarak antara sensor dengan objek. Ilustrasi gambar prinsip kerja sensor ultrasonik dapat dilihat pada gambar 4. ${ }^{[4]}$

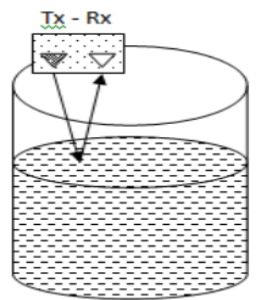

Gambar 4.Prinsip Kerja Sensor Ultrasonik

\section{Optocoupler}

Optocoupler adalah komponen elektronika yang berfungsi sebagai penghubung berdasarkan cahaya optik. ${ }^{[5]}$ Pada dasarnya Optocoupler terdiri dari 2 bagian utama yaitu Transmitter yang berfungsi sebagai pengirim cahaya optik dan Receiver yang berfungsi sebagai pendeteksi sumber cahaya.Masing-masing bagian Optocoupler (Transmitter dan Receiver) tidak memiliki hubungan konduktif rangkaian secara langsung tetapi dibuat sedemikian rupa dalam satu kemasan komponen.

Pada prinsipnya, Optocoupler dengan kombinasi LED-Phototransistor adalah Optocoupler yang terdiri dari sebuah komponen LED (Light Emitting Diode) yang memancarkan cahaya infra merah (IR LED) dan sebuah komponen semikonduktor yang peka terhadap cahaya (Phototransistor) sebagai bagian yang digunakan untuk mendeteksi cahaya infra merah yang dipancarkan oleh IR LED.Untuk lebih jelas mengenai Prinsip kerja Optocoupler, rangkaian internal komponen Optocoupler dapat dilihat pada gambar 5 .

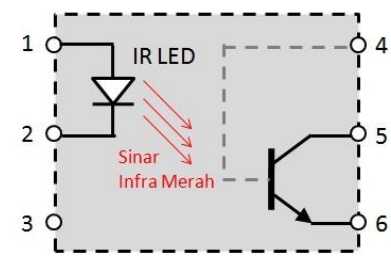

Gambar 5.Prinsip Kerja Optocoupler

\section{PERANCANGAN SISTEM \\ Blok DiagramRangkaian}

Gambar 3.1 menunjukan blok diargam keseluruhan.

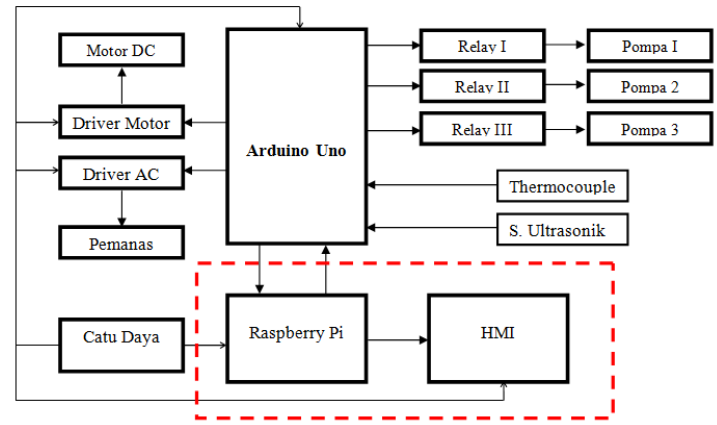

Gambar 6. Blok Diagram Keseluruhan

Suatu sistem memiliki tiga unsur utama, yaitu input (masukan), proses, dan output (keluaran). Berdasarkan blok diagram sistem diatas dapat dijabarkan sebagai berikut:

- Sebagai piranti inputan ke Arduino, digunakan sensor water level control(sensor ultrasonic)dan sensor suhu (Thermocouple ) yang langsung terhubung ke Arduino sebagai inputan untuk mengontrol pompa air dan pemanas yang diatur dari Arduino uno. Human Machine Interface (HMI) juga digunakan sebagai inputan data untuk pengaturan nilai water level controldan sensor thermocouple.

- Arduinodigunakan sebagai pengendali inputan dan outputan system.

- Sebagai piranti keluaran dari Arduino, digunakan pemanas, motor pengaduk, relay pompa air dan Human Machine Interface (HMI). HMI digunakan sebagai alat visualisasi dalam proses kinerja pada rangkaian.

\section{Rangkaian Driver Motor DC}

Motor DC adalah suatu piranti elektronik yang befungsi untuk mengubah energi listrik menjadi energi mekanik. Pada aplikasi rancang bangun batch mixer ini menggunakan motor DC 
sebagai alat penggeraknya(pengaduknya), karena jenis motor ini lebih mudah untuk dikendalikan. Kecepatan yang dihasilkan oleh motor DC berbanding lurus dengan potensial yang diberikan. Motor dc tidak dapat dikendalikan langsung melalui mikrokontroller karena membutuhkan arus listrik yang cukup besar untuk menggerakan motor dc sedangkan keluaran dari mikrokontroller sangat kecil.

Maka driver motor merupakan pilihan alternatif yang digunakan untuk mengendalikan motor dc. Ada beberapa tipe driver motor yang disering digunakan yaitu menggunakan $\mathrm{H}$-bridge transistor, H-bridge Mosfet, dan ic driver motor. Pada rangkaian driver ini digunakan 1 buah transistor 2N3904 tipe NPN dan mosfet IRF540 tipe $\mathrm{N}$ sebagai drivernya dengan beban motor dc 12 V.
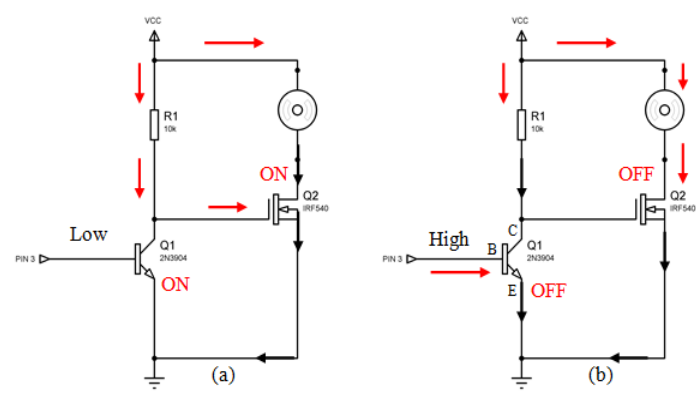

Gambar 7.Rangkaian Driver Motor

Gambar (a)

: Karena transistor yang dipakai adalah transistor jenis NPN maka, ketika kaki basis (B) transistor diberi nilai low dari arduino uno, transistor akan aktif dan arah arus dari kaki kolektor (C) ke emitor (E) akan terputus sehingga arus mengalir ke arah mosfet IRF540 tipe $\mathrm{N}$, dan tegangan dari vcc mengaktifkan kaki gate mosfet untuk menyalakan motor.

Gambar (b) : Ketika kaki basis (B) transistor diberi nilai high dari arduino uno, maka transistor OFF dan arah arus dari kaki kolektor (C) ke emitor (E) akan terhubung sehingga arus tidak mengalir ke arah mosfet dan motor akan mati.

\section{Rangkaian Driver Tegangan AC}

Driver AC kontrol pemanas air sebagai antarmuka antara mikrokontroler dengan rangkaian daya menggunakan tegangan AC. Tegangan AC digunakan untuk menghidupkan beban $\mathrm{AC}$, seperti heater air yang dikendalikan oleh mikrokontroler Arduino Uno. Sistem kontrol yang digunakan yaitu kontrol tegangan AC secara sudut fasa dengan triac. Sumber tegangan AC yang terhubung dengan triac digunakan untuk merubah atau mengatur besar daya yang diberikan pada heater sesuai besar suhu aktual yang terbaca oleh sensor Thermocouple. Driver AC kontrol pemanas air berfungsi untuk mempertahankan tegangan yang diinginkan agar tetap stabil dan mengurangi error, driver kontrol pemanas air dapat dilihat pada gambar 8 .

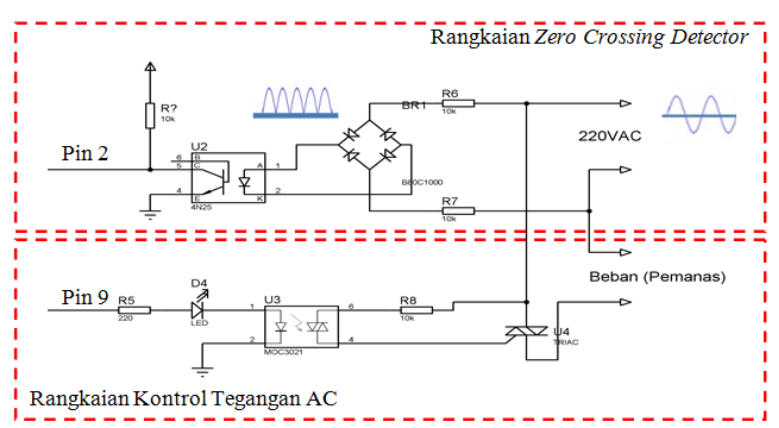

Gambar 8. Rangkaian Driver AC

Prinsip kerja rangkaian ini adalah ketika mendapat masukan tegangan AC 220 Volt akan melewati resistor pembagi tegangan kemudian tegangan diturunkan sehingga membutuhkan arus yang kecil. Optocoupler 4N25 berfungsi untuk mendeteksi zero crossing detector.

Berhubung optocoupler 4N25 hanya bisa dioperasikan pada tegangan DC maka terlebih dahulu tegangan AC disearahkan melalui diode bridge. Periode dari sinyal output penyearah gelombang penuh sama dengan periode sinyal input. Setiap siklus input menghasilkan satu siklus output sehingga frekuensi output sama dengan frekuensi inputnya.

fout $=$ fin

Meskipun sudah tegangan DC masih memiliki ripple sehingga tegangan tetap bisa dibaca kapan terjadi di titik nolnya. Waktu terbaca di titik nol, zero crossing detector kemudian mengirim sinyal ke mikrokontroler Arduino Uno telah terjadi perpotongan pada persimpangan positif ke positif. Ketika mendeteksi titik persilangan nol (zero crossing detector), maka LED mati dan receiver menerima sinyal maka photodiode akan off sehingga output kolektor akan berlogika high. Selanjut sinyal akan di kirim ke mikrokontroler Arduino Uno untuk diproses sebagai acuan yang digunakan untuk awal pemberian waktu tunda dan menghasilkan output duty cycle pada PWM.

\section{Rangkaian Driver Relay}

Pompa merupakan alat yang digunakan untuk memindahkan air dari tempat ke tempat lain dengan cara menaikkan volume air tersebut. Rangkaian driver pompa dalam sistem ini digunakan sebagai pemindah air serta mengatur volume air saat mengisi tangki. Driver pompa terdiri dari sebuah resistor, transistor dan diode yang berfungsi sebagai relay untuk menghubungkan rangkaian beban on atau off.

Transistor berfungsi sebagai saklar, ketika mendapat tegangan pada basisnya transistor akan menghubungkan kolektor dan emitornya sehingga relay dapat tegangan dan melakukan switch. Pompa air akan aktif pada saat volume air dalam tangki air rendah sampai volume air dalam tangki air penuh hal tersebut sesuai dengan perintah mikrokontroler 
Arduino Uno yang diterima dari sensor ultrasonic sebagai water level control. Kerja pompa air akan mengatur ketinggian air di tandon, karena volume tertentu otomatis relay akan dinyalakan untuk memompa air. Rangkaian relay dapat dilihat pada gambar 9.

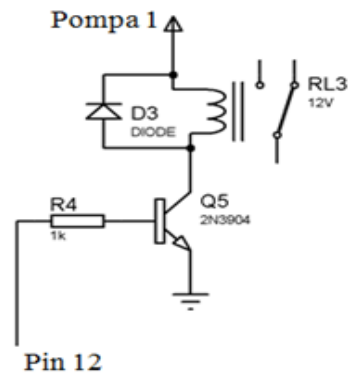

Gambar 9.Rangkaian Driver Relay

Vec pada rangkaian driver pompa, relay di atas terhubung dengan outputmikrokontroler Arduino Uno dan ground terhubung dengan ground Arduino Uno juga. Sedangkan output relay terhubung dengan kontaktor.Cara kerja dari relay tersebut adalah, ketika Arduino Uno memberi perintah (output) maka tegangan yang keluar dari Arduino Uno akan menggerakkan koil pada relay untuk menarik kontak utama, sehingga ketika relay bekerja dari normally open (NO) menjadi normally close (NC).

\section{PENGUJIAN SISTEM}

Pengujian dilakukan pada masing-masing rangkaian. Hal itu bertujuan untuk mendeteksi kemungkinan adanya kesalahan pada rangkaian. Selain itu juga untuk mengetahui nilai besaran listrik keluarannya.

\section{Sensor Ultrasonik}

Pengukuran sensor ultrasonik dilakukan guna mengetahui sensitifitas sensor. Pengkuran terhadap sensor Ultrasonic dilakukan dengan mengukur jarak zat cair pada tangki 1 terukur yang diletakkan di hadapan sensor, pembacaan sensor dibatasi pada jarak $10 \mathrm{~cm}-27 \mathrm{~cm}$. selain itu pengukuran juga dilakukan dengan menggunakan mistar sebagai bahan perbandingan terhadap sensitifitas sensor ultrasonik. Hasil pengukuran sensor dapat dilihat pada tabel 1 .

Tabel 1. Hasil Pengujian Sensor Ultrasonik

\begin{tabular}{lllll}
\hline No & $\begin{array}{l}\text { Ketinggian } \\
\text { terukur } \\
\text { mistar } \\
(\mathrm{cm})\end{array}$ & $\begin{array}{l}\text { Sensor } \\
\text { ultrasonik }\end{array}$ & Selisih & $\begin{array}{l}\text { Error } \\
(\%)\end{array}$ \\
\hline 1 & 5 & 5.6 & 0.6 & 0.12 \\
2 & 7 & 7.1 & 0.1 & 0.14 \\
3 & 11 & 11.3 & 0.3 & 2.7 \\
4 & 17 & 17.5 & 0.5 & 2.9 \\
5 & 23 & 23.1 & 0.1 & 0.4 \\
\hline
\end{tabular}

Berdasarkan tabel 1. pembacaan sensor ultrasonik untuk pengujian ini memilikinilai error maksimum 2,9 \% terhadap ketinggian terukur mistar. Hal ini disebabkan karena posisi sensor, kondisi elektronika dan juga keadaan air yang kurang stabil.

\section{Rangkaian Thermocouple}

Pengujian pembacaan sensor Thermocouple dilakukan dengan mengukur suhu pada plant yang dibandingkan dengan pembacaan pengukuran thermometer. Data hasil pengukuran yang dilakukan pada tabel 2.

Tabel 2. Pengujian Sensor Thermocouple

\begin{tabular}{lllll}
\hline $\begin{array}{l}\mathrm{N} \\
\mathrm{o}\end{array}$ & $\begin{array}{l}\text { Suhu } \\
\text { terukur } \\
\text { thermomete } \\
\mathrm{r}\left({ }^{0} \mathrm{C}\right)\end{array}$ & $\begin{array}{l}\text { Sensor } \\
\text { thermocoupl }\end{array}$ & $\begin{array}{l}\text { Selisi } \\
\mathrm{h}\end{array}$ & $\begin{array}{l}\text { Erro } \\
\mathrm{r}(\%)\end{array}$ \\
\hline 1 & 30 & 30.3 & 0.3 & 1 \\
2 & 40 & 40.79 & 0.79 & 1.9 \\
3 & 50 & 50.1 & 0.1 & 0.2 \\
4 & 60 & 60.21 & 0.21 & 0.35 \\
5 & 70 & 70.41 & 0.41 & 0.5 \\
6 & 80 & 80.30 & 0.3 & 0.3 \\
7 & 90 & 90.80 & 0.8 & 0.8 \\
8 & 100 & 100.2 & 0.2 & 0.2 \\
\hline
\end{tabular}

Berdasarkan tabel 2. dapat disimpulkan bahwa pembacaan sensor untuk pengujian ini dibatasi pada range suhu 30 oC -100 oC dengan memiliki nilai error maksimum $1,9 \%$ terhadap suhu terukur thermometer. Hal ini disebabkan oleh perubahan tegangan pada setiap rangkaian elektronika dan juga posisi pembacaan sensor Thermocouple yang berubah-ubah.

\section{Rangkaian Kontrol Tangan AC}

Pada dasarnya tujuan pengukuran rangkaian driver AC adalah bertujuan untuk mengetahui keluaran akhir dari rangkaian driver $\mathrm{AC}$ agaroutput tegangan AC sesuai yang dibutuhkan. Driver AC menggunakan PWM (Pulse Width Modulation) dari mikrokontroler Arduino Uno yang akan menentukan besar duty cycle untuk mempengaruhi proses pemanasan heater. Proses pemanasan tergantung dari besar arus dan daya yang diberikan output yang diatur dari inputan PWM yang diberikan. Data hasil pengukuran dapat dilihat pada tabel 3.

Tabel 3. Duty CyclePengukuran PWM

\begin{tabular}{lllll}
\hline No & $\begin{array}{l}\text { Nilai } \\
\text { PWM }\end{array}$ & $\begin{array}{l}\text { Tegangan } \\
\text { AC }\end{array}$ & $\begin{array}{l}\text { Arus } \\
(\mathrm{A})\end{array}$ & $\begin{array}{l}\text { Duty } \\
\text { cycle } \\
(\%)\end{array}$ \\
\hline 1 & 25 & 23 & 0.23 & 9.8 \\
2 & 50 & 37 & 0.35 & 19 \\
3 & 75 & 66 & 0.6 & 29 \\
4 & 100 & 100 & 0.84 & 39 \\
5 & 125 & 133 & 1.06 & 49 \\
\hline
\end{tabular}




\begin{tabular}{lllll}
\hline 6 & 150 & 164 & 1.24 & 58 \\
7 & 175 & 188 & 1.42 & 68 \\
8 & 200 & 206 & 1.48 & 78 \\
9 & 225 & 218 & 1.54 & 88 \\
10 & 255 & 220 & 1.55 & 100 \\
\hline
\end{tabular}

\section{Rangkaian Driver Motor}

Pengukuran dilakukan bertujuan untuk mengetahui apakah driver motor berkerja dengan baik sesuai yang diharapkan. Pada rangkaian driver motor ini digunakan 1 buah transistor 2N3904 tipe NPN dan mosfet IRF540 tipe N sebagai drivernya dengan beban motor dc $12 \mathrm{~V}$. Pengukuran dilakukan dalam kondisi berbeban dan tidak berbeban. Hasil pengukuran dapat dilihat pada tabel 4 dan tabel 5.

Tabel 4. Pengukuran Driver Motor DC

\begin{tabular}{lcc}
\hline \multirow{2}{*}{ Kondisi } & \multicolumn{2}{c}{ Tegangan } \\
& Vcc & Motor \\
\hline Berbeban & $12.13 \mathrm{~V}$ & $12.1 \mathrm{~V}$ \\
$\begin{array}{l}\text { Tidak } \\
\text { berbeban }\end{array}$ & $12.13 \mathrm{~V}$ & $0 \mathrm{~V}$ \\
\hline
\end{tabular}

Tabel 5.Pengukuran Transistor IRF540

\begin{tabular}{lccc}
\hline \multirow{2}{*}{$\begin{array}{c}\text { Kondisi } \\
\text { Mosfet }\end{array}$} & $\begin{array}{c}\text { Gate-GND } \\
\text { (V) }\end{array}$ & $\begin{array}{c}\text { Drain- } \\
\text { GND } \\
\text { IRF540 }\end{array}$ & $\begin{array}{c}\text { Source } \\
(\mathrm{V})\end{array}$ \\
\hline ON & 12.1 & 0 & 0 \\
OFF & $0 \mathrm{~V}$ & 12.01 & 0 \\
\hline
\end{tabular}

\section{Pengujian Kontrol PID}

Pengujian Proportional Integral Derivatif (PID) dilakukan untuk mengetahui apakan rumusan yang digunakan dalam pembuatan kendali PID dapat berjalan sesuai yang diharapkan. Untuk mengetahui grafik respon PID terhadap suhu set point maka dibutuhkan nilai $\mathrm{Kp}, \mathrm{Kd}$, dan $\mathrm{Ki}$ yang didapat dari metode tuning PID agar suhu set point sesuai dengan yang diharapkan seperti pada tabel 6 .

Tabel 6. Data Percobaan dalam Penentuan Nilai Kp, Ki, Kd

\begin{tabular}{cccccccccc}
\hline No & $\mathrm{Kp}$ & $\mathrm{Ki}$ & $\mathrm{Kd}$ & $\begin{array}{c}\text { Overshoot } \\
\left({ }^{0} \mathrm{C}\right)\end{array}$ & $\%$ & $\begin{array}{c}\text { Undershoot } \\
\left({ }^{0} \mathrm{C}\right)\end{array}$ & $\%$ & $\begin{array}{c}\text { Steady } \\
\text { state error }\end{array}$ & $\%$ \\
\hline 1 & 10 & 1 & 0.1 & 12.39 & 27.5 & 0 & 0 & N/A & N/A \\
2 & 10 & 0.005 & 0.5 & 0 & 0 & 7.35 & 16 & N/A & N/A \\
3 & 10 & 0.005 & 1 & 0 & 0 & 4.15 & 9.2 & N/A & N/A \\
4 & 30 & 0.5 & 0.1 & 6.72 & 14.9 & 0 & 0 & N/A & N/A \\
5 & 30 & 0.0005 & 0.1 & 0 & 0 & 10.36 & 24 & N/A & N/A \\
6 & 50 & 0.0001 & 1 & 0 & 0 & 4.25 & 6.2 & N/A & N/A \\
7 & 50 & 1 & 0.5 & 6.39 & 14.2 & 0 & 0 & N/A & N/A \\
8 & 60 & 0.01 & 0.5 & 1.74 & 3.8 & 0 & 0 & N/A & N/A \\
9 & 60 & 0.005 & 0.5 & 0 & 0 & 0 & 0 & 1 & 2 \\
10 & 80 & 0.01 & 0.5 & 1.14 & 2.5 & 0 & 0 & N/A & N/A \\
\hline
\end{tabular}

Dari hasil tuning PID didapat nilai $\mathrm{Kp}=60$, $\mathrm{Ki}=0,005$, dan $\mathrm{Kd}=0,5$ dalam bentuk grafik respon dapat dilihat pada Gambar 10.

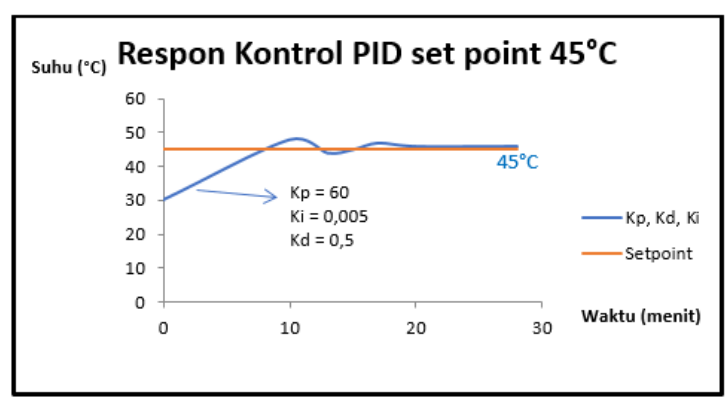

Gambar 10. Respon Kontrol PID set point $45^{\circ} \mathrm{C}$
Tabel 7. Pengujian Kontrol PID terhadap Suhu

\begin{tabular}{lllll}
\hline No & $\begin{array}{l}\text { Set } \\
\text { point } \\
\left({ }^{0} \mathrm{C}\right)\end{array}$ & $\begin{array}{l}\text { Suhu } \\
\text { tampilan } \\
\left({ }^{0} \mathrm{C}\right)\end{array}$ & $\begin{array}{l}\text { Selisih } \\
\left({ }^{0} \mathrm{C}\right)\end{array}$ & $\begin{array}{l}\text { Error } \\
(\%)\end{array}$ \\
\hline 1 & 30 & 30.4 & 0.4 & 1.3 \\
2 & 35 & 36 & 1 & 2.5 \\
3 & 40 & 40.4 & 0.4 & 1 \\
4 & 45 & 46 & 1 & 2 \\
5 & 50 & 51.1 & 1.1 & 2.2 \\
\hline
\end{tabular}

Hasil pengujian ini menunjukkan bahwa pengendalian suhu air dengan metode kontrol PID menghasilkan respon sesuai dengan yang diharapkan dan mampu diaplikasikan pada sistem pengendalian suhu karena error yang didapatkan maksimal sebesar $2,5 \%$ dan masih dalam toleransi. 


\section{Rangkaian Gelombang PWM}

Pengujian Pulse Width Modulation (PWM)dilakukan untuk mengetahui gelombang keluaran yang dihasilkan dari perhitungan PID.PWM adalah keluaran yang dihasilkan dari perhitungan kontrol PID yang mempengaruhi sudut penyalaan TRIAC untuk mengontrol daya pada heater . Pengujian dilakukan dengan memberikan nilai manual PWM dari Duty Cycle0 - 255 (0\% $100 \%)$. Sampling hasil pengujian untuk tiga kali nilai besar duty cycle PWM ditunjukkan pada gambar 11-gambar 13.

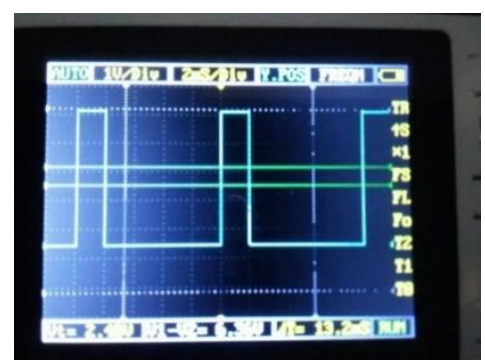

Gambar 11. Duty CyclePWM 25

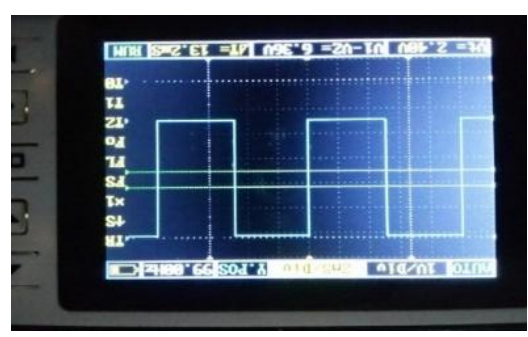

Gambar 12. Duty CyclePWM 100

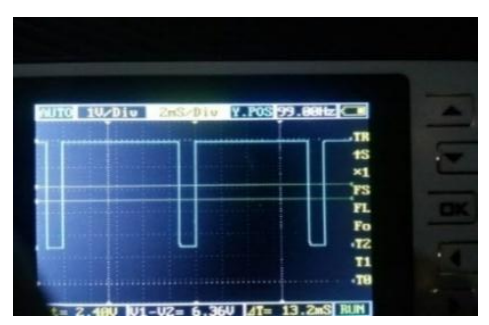

Gambar 13. Duty CyclePWM 200

\section{KESIMPULAN}

Berdasarkan hasil pengujian yang telah dilakukan terhadap rancang bangun sistem kontrol Batch Mixerpada industri minuman menggunakan metode PID berbasis Arduino Uno R3, maka dapat ditarik beberapa kesimpulan diantaranya :

- Berdasarkan data yang diperoleh dari pengujian sensor ultrasonik, dapat disimpulkan bahwa sensor ultrasonik memiliki nilai error maksimum 2,9 \% terhadap nilai ketinggian terukur mistar.

- Berdasarkan hasil pengujian nilai error maksimum yang ditunjukan oleh sensor thermocoupledisimpulkan bahwa pembacaan sensor untuk pengujian yang dibatasi pada range suhu $30 \mathrm{oC}-100 \mathrm{oC}$ memiliki nilai error maksimum $1,9 \%$ terhadap suhu terukur thermometertidak melebihi batas toleransi yang ditentukan sebesar 3\% .

- Berdasarkan data respon sistem yang diperoleh dari pengujian dengan metode hand tunning, untuk menghasilkan respon yang diinginkan maka parameter kontroler PID dapat ditentukan dengan $\mathrm{Kp}=60, \mathrm{Ki}=0.005$, dan $\mathrm{Kd}=0,5$.

- Hasil pengujian ini menunjukkan bahwa pengendalian suhu air dengan metode kontrol PID menghasilkan respon sesuai dengan yang diharapkan dan mampu diaplikasikan pada sistem pengendalian suhu karena error yang didapatkan maksimal sebesar 2,5\% masih pada batas toleransi.

\section{DAFTAR PUSTAKA}

1. Bishop, Owen. 2004, Sistem Instrumentasi dan Sistem Kontrol, Jakarta:Erlangga

2. Setiawan, Iwan. 2008. Kontrol PID Untuk Proses Industri, Tidak Diterbitkan. Jakarta: Alex Media Komputindo.

3. Arduino, 2015, Arduino Board Uno, http://arduino.cc/en/Main/ArduinoBoardUno\# (diakses tanggal 5 Oktober 2016)

4. Syaifunnajib, Ahmad. 2013. Prototipe Alat Pencampuran Minuman Otomatis Berbasis Mikrokontroler Atmega16, Tugas Akhir. S1 Teknik Elektro. Tidak Diterbitkan. Yogyakarta: UNY

5. Mundari, Ade. 2011. Alat Pengaduk Dan Pemanas Terintegrasi Temperatur dan Kecepatan Terkendali Berbasis Mikrokontroller. Tugas Akhir. S1 Teknik Fisika. Tidak Diterbitkan. Depok: Universitas Indonesia 